\title{
Assessment of Genetic Diversity in Extra Large and Large Seeded Kabuli Chickpea
}

\author{
B. Manasa*, M. Shanthi Priya, V. Jayalakshmi and P. Umamaheswari
}

Acharya N.G. Ranga Agricultural University, Guntur, India

*Corresponding author

A B S T R A C T

\begin{tabular}{l} 
Key w o r d s \\
$\begin{array}{l}\text { Kabuli chickpea, } \\
\text { Yield, Diversity and } \\
\text { cooking quality }\end{array}$ \\
Article Info \\
\hline $\begin{array}{l}\text { Accepted: } \\
\text { 10 March } 2020 \\
\text { Available Online: } \\
\text { 10 April } 2020\end{array}$ \\
\hline
\end{tabular}

\section{Keywords}

Kabuli chickpea, Yield, Diversity and cooking quality

\section{Introduction}

Chickpea is one of the earliest food legumes cultivated. During the last five decades, its production has increased significantly which is primarily due to introduction of high yielding and disease resistant varieties and adoption of improved production technologies. India is the largest chickpea producer and consumer in the world. Among desi and kabuli, large seeded kabuli types have more consumer preference and hence fetch premium price to the farmers. Fortunately, the trading of extra-large seeded kabuli types is dominating the international market. Approximately one million tons of chickpea were imported by Government, private organizations and other agencies. But the large seeded kabuli chickpea with high yields is a rare combination so far.

For this, genetic divergence among the parents can play a vital role in cultivar improvement because crosses involving genetically diverse parents are likely to produce high heterotic effects and also more variability in segregating generations when involved in hybridization programmes. Thus, the present investigation was a step to find the possible crosses by estimating the genetic divergence among 30 genotypes using Mahalanobis $\mathrm{D}^{2}$ statistic for 19 traits. 


\section{Results and Discussion}

\section{Clustering of genotypes by tocher method}

Based on the cluster analysis, 30 genotypes were grouped into six clusters under rainfed condition as presented in the Table 1 and Fig. 1. The highest number of genotypes i.e nine was found in cluster I and II. The other clusters viz., cluster III and IV were with five genotypes and cluster $\mathrm{V}$ and VI were monogenotypic.

\section{Inter and intra cluster distances}

The average inter and intra cluster distances were presented in the Table 1 and Fig. 2 . The range of inter cluster distance varied from 182.68 to 1696.22 which is higher than the range of Intra cluster distance varied from 0.00 to 162.98 . Similar results were also reported by Syed et al., (2012), Jain and Indapurkar (2013), Puri et al., (2013), Jayalakshmi et al., (2014), Singh et al., (2016), Vijayakumar et al., (2017), Gediya et $a l$. , (2018). The highest inter cluster distance was observed between clusters IV and VI (1696.22), followed by II and VI (959.81), V and VI (950.94), I and IV (742.12) which indicated that the genotypes grouped in these clusters were highly divergent from each other.

While, the lowest inter cluster distance was found between cluster II and V (182.68), followed by cluster II and IV (241.68), cluster IV and V (266.54), cluster I and III (276.12) which indicated that the genotypes grouped in these clusters were less divergent from each other.

The maximum intra cluster distance was shown by cluster IV (162.98), followed by cluster III (130.18), cluster II (107.57) and cluster I (103.34). The clusters V and VI were monogenotypic and hence recorded zero intra cluster distance.

\section{Cluster means for various characters}

The cluster means obtained for 19 traits were presented in Table 2. Cluster means for days to $50 \%$ flowering ranged from 41.89 days to 57.13. The early flowering of 41.89 days was observed in the genotypes of cluster I and the delayed flowering of 57.13 days was recorded in the genotypes of cluster III.

Cluster means for days to physiological maturity ranged from early maturity of 76.78 days to late maturity of 89.93 days in the genotypes belonging to cluster I and cluster III, respectively.

SCMR cluster means ranged from maximum of 58.60 to minimum of 47.08 in the genotypes of cluster VI and cluster III, respectively.

The maximum value of cluster means of plant height observed in the genotypes of cluster $\mathrm{V}$ was $48.53 \mathrm{~cm}$ and the minimum value of cluster means of plant height observed in the genotypes of cluster I was $37.30 \mathrm{~cm}$.

Cluster means for number of primary branches per plant ranged from maximum of 3.1 to minimum of 2.67 in the genotypes belonging to cluster $\mathrm{VI}$ and cluster $\mathrm{V}$, respectively.

Number of secondary branches per plant cluster means ranged from maximum of 10.53 to minimum of 8.43 in the genotypes of cluster II and cluster III, respectively.

The genotypes in the cluster IV and cluster VI showed maximum value of 18.61 and minimum value of 11.01 for number of pods per plant, respectively. Cluster means for number of seeds per plant ranged from 24.55 to 15.33 . The maximum value of 24.55 was recorded in the genotypes of cluster IV and the minimum value of 15.33 was observed in the genotypes of cluster VI. 
Cluster means for seed diameter ranged from maximum of $8.47 \mathrm{~mm}$ to minimum of 7.53 $\mathrm{mm}$ in the genotypes belonging to cluster $\mathrm{V}$ and cluster IV, respectively.

The maximum value of cluster means for protein content observed in the genotypes of cluster III was $20.5 \%$ and the minimum value of cluster means of protein content observed in the genotypes of cluster VI was $15.2 \%$.

The genotypes in the cluster VI showed maximum value of $39.33 \mathrm{ml}$ and the genotypes in the cluster III and IV showed minimum value of $29.33 \mathrm{ml}$ for 100 grain volume.

Cluster means for water absorption after soaking ranged from maximum of $60.81 \%$ to minimum of $51.98 \%$ in the genotypes of cluster V and cluster IV, respectively.

The maximum value of cluster means for volume expansion after soaking observed in the genotypes of cluster $\mathrm{V}$ was $67.56 \%$ and the minimum value observed in the genotypes of cluster VI was $54.15 \%$.

Cluster means for cooking time for raw seeds ranged from a less time of $94.7 \mathrm{~min}$ to more time of $121.33 \mathrm{~min}$ in the genotypes belonging to cluster II and cluster V, respectively.

Cluster means for cooking time for soaked seeds ranged from 58.33 to $36.33 \mathrm{~min}$. The less time of 36.33 min was observed in the genotypes of cluster $\mathrm{V}$ and the more time of 58.33 min was recorded in the genotypes of cluster VI.

The genotypes in the cluster $\mathrm{V}$ and cluster III showed maximum value of $47.33 \mathrm{~g}$ and minimum value of $37.43 \mathrm{~g}$ for 100 seed weight, respectively.
The maximum value of cluster means for shoot biomass per plant observed in the genotypes of cluster III was $18.47 \mathrm{~g}$ and the minimum value observed in the genotypes of cluster VI was $15.76 \mathrm{~g}$.

Cluster means for harvest index ranged from $45.29 \%$ to $28.35 \%$. The maximum of $45.29 \%$ was observed in the genotypes of cluster I and minimum of $28.35 \%$ was observed in the genotypes of cluster III.

Cluster means for seed yield per plant ranged from a maximum of $7.59 \mathrm{~g}$ to minimum of $5.22 \mathrm{~g}$ in the genotypes belonging to cluster IV and cluster III, respectively.

In a nut shell, genotypes of cluster $\mathrm{V}$ exhibited high cluster means for traits like plant height, seed diameter, water absorption after soaking, volume expansion after soaking, cooking time for soaked seeds and 100 seed weight, followed by cluster VI with superior cluster means for SCMR, number of primary branches per plant, 100 grain volume and cluster IV with excelled cluster means for number of pods per plant, number of seeds per plant, seed yield per plant and cluster I with superior cluster means for days to $50 \%$ flowering, days to physiological maturity, harvest index, followed by cluster III with higher cluster means for protein content, shoot biomass per plant and cluster II with superior cluster means for number of secondary branches per plant and cooking time for raw seeds.

\section{Relative contribution of each character towards genetic divergence}

The number of times each of the 19 characters appeared first and their respective percentage of relative contribution towards genetic divergence were presented in Table 3. 
Table.1 Distribution of 30 genotypes of chickpea into different clusters under rainfed condition

\begin{tabular}{|l|c|l|}
\hline $\begin{array}{c}\text { Cluster } \\
\text { No. }\end{array}$ & $\begin{array}{c}\text { No. of } \\
\text { genotypes }\end{array}$ & \\
\hline I & 9 & $\begin{array}{l}\text { NBeG 835, ICCV 171301, NBeG 837, NBeG 810, NBeG 723, ICCV 171305, NBeG 719, } \\
\text { NBeG 119, Phule G 15307 }\end{array}$ \\
\hline II & 9 & $\begin{array}{l}\text { NBeG 399, NBeG 724, NBeG 458, NBeG 789, KAK 2, NBeG 829, NBeG 833, NBeG 440, } \\
\text { NBeG 844 }\end{array}$ \\
\hline III & 5 & ICCV 171302, ICCV 171306, JGK 5, RKGK 499, ICCV 171303 \\
\hline IV & 5 & ICCV 177314, Vihar, NBeG 1010, ICCV 171313, Phule G 0517 \\
\hline V & 1 & MNK 1 \\
\hline VI & 1 & NBeG 805 \\
\hline
\end{tabular}

Table.2 Average inter and intra cluster distances in 30 chickpea genotypes under rainfed condition

\begin{tabular}{|l|c|c|c|c|c|c|}
\hline & Cluster 1 & Cluster 2 & Cluster 3 & Cluster 4 & Cluster 5 & Cluster 6 \\
\hline Cluster 1 & 103.34 & 298.97 & 276.12 & 742.12 & 390.23 & 340.76 \\
\hline Cluster 2 & & 107.57 & 345.04 & 241.68 & 182.68 & 959.81 \\
\hline Cluster 3 & & & 130.18 & 626.88 & 294.33 & 537.37 \\
\hline Cluster 4 & & & & 162.98 & 266.54 & 1696.22 \\
\hline Cluster 5 & & & & & 0 & 950.94 \\
\hline Cluster 6 & & & & & & 0 \\
\hline
\end{tabular}


Table.3 Cluster means for 19 characters in 30 chickpea genotypes under rainfed condition

\begin{tabular}{|c|c|c|c|c|c|c|c|}
\hline S.No. & Characters & Cluster 1 & Cluster 2 & Cluster 3 & Cluster 4 & Cluster 5 & Cluster 6 \\
\hline 1 & Days to $50 \%$ flowering & 41.89 & 43.59 & 57.13 & 47.80 & 52.00 & 46.00 \\
\hline 2 & Days to physiological maturity & 76.78 & 78.48 & 89.93 & 81.20 & 87.67 & 79.67 \\
\hline 3 & SCMR & 50.05 & 51.26 & 47.08 & 48.37 & 48.10 & 58.60 \\
\hline 4 & Plant height $(\mathrm{cm})$ & 37.30 & 38.44 & 40.27 & 38.29 & 48.53 & 37.87 \\
\hline 5 & No. of primary branches per plant & 3.00 & 3.09 & 2.98 & 2.89 & 2.67 & 3.10 \\
\hline 6 & No. of secondary branches per plant & 10.09 & 10.53 & 8.43 & 9.74 & 8.52 & 9.59 \\
\hline 7 & No. of pods per plant & 15.99 & 17.70 & 12.58 & 18.61 & 14.32 & 11.01 \\
\hline 8 & No. of seeds per plant & 20.09 & 20.54 & 15.97 & 24.55 & 18.33 & 15.33 \\
\hline 9 & Seed diameter $(\mathrm{mm})$ & 8.05 & 7.67 & 7.81 & 7.53 & 8.47 & 8.00 \\
\hline 10 & Protein content (\%) & 18.80 & 16.98 & 20.50 & 18.30 & 16.63 & 15.20 \\
\hline 11 & 100 grain volume $(\mathrm{ml})$ & 35.04 & 32.56 & 29.93 & 29.93 & 34.67 & 39.33 \\
\hline 12 & Water absorption after soaking (\%) & 54.33 & 55.10 & 57.10 & 51.98 & 60.81 & 56.13 \\
\hline 13 & Volume expansion after soaking (\%) & 58.15 & 57.23 & 62.56 & 58.76 & 67.56 & 54.15 \\
\hline 14 & Cooking time for raw seeds (min) & 98.74 & 94.70 & 105.20 & 100.73 & 121.33 & 118.00 \\
\hline 15 & $\begin{array}{l}\text { Cooking time for soaked seeds } \\
\text { (min) }\end{array}$ & 50.41 & 41.44 & 45.93 & 38.07 & 36.33 & 58.33 \\
\hline 16 & 100 seed weight $(\mathrm{g})$ & 43.30 & 39.96 & 37.43 & 39.33 & 47.33 & 42.33 \\
\hline 17 & Shoot biomass per plant (g) & 16.33 & 16.46 & 18.47 & 18.24 & 17.52 & 15.76 \\
\hline 18 & Harvest index (\%) & 45.29 & 44.37 & 28.35 & 41.56 & 42.60 & 33.28 \\
\hline 19 & Seed yield per plant (g) & 7.39 & 7.31 & 5.22 & 7.59 & 7.50 & 5.62 \\
\hline
\end{tabular}




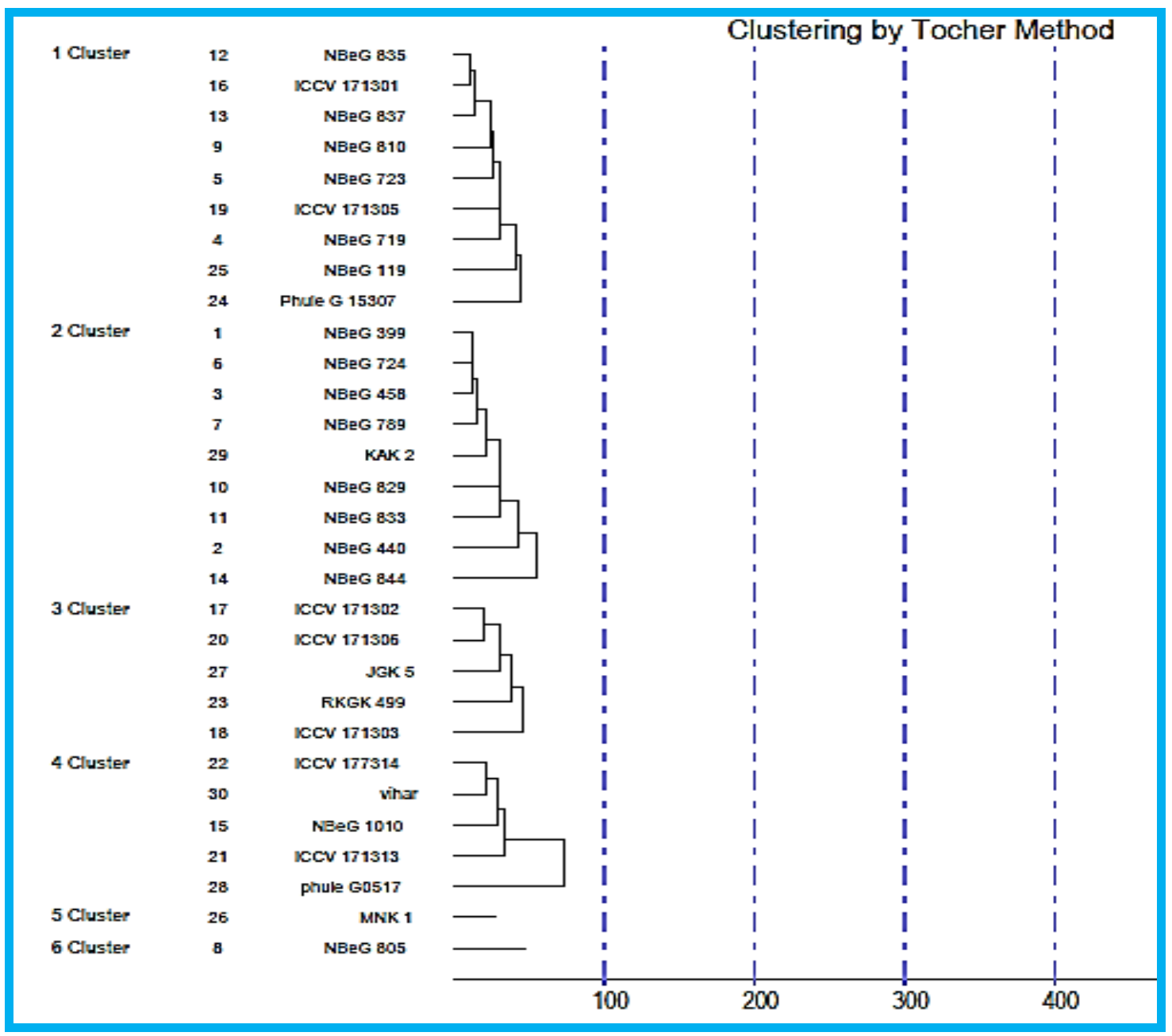

Fig.1 Grouping of genotypes into clusters using Tocher's method under rainfed condition

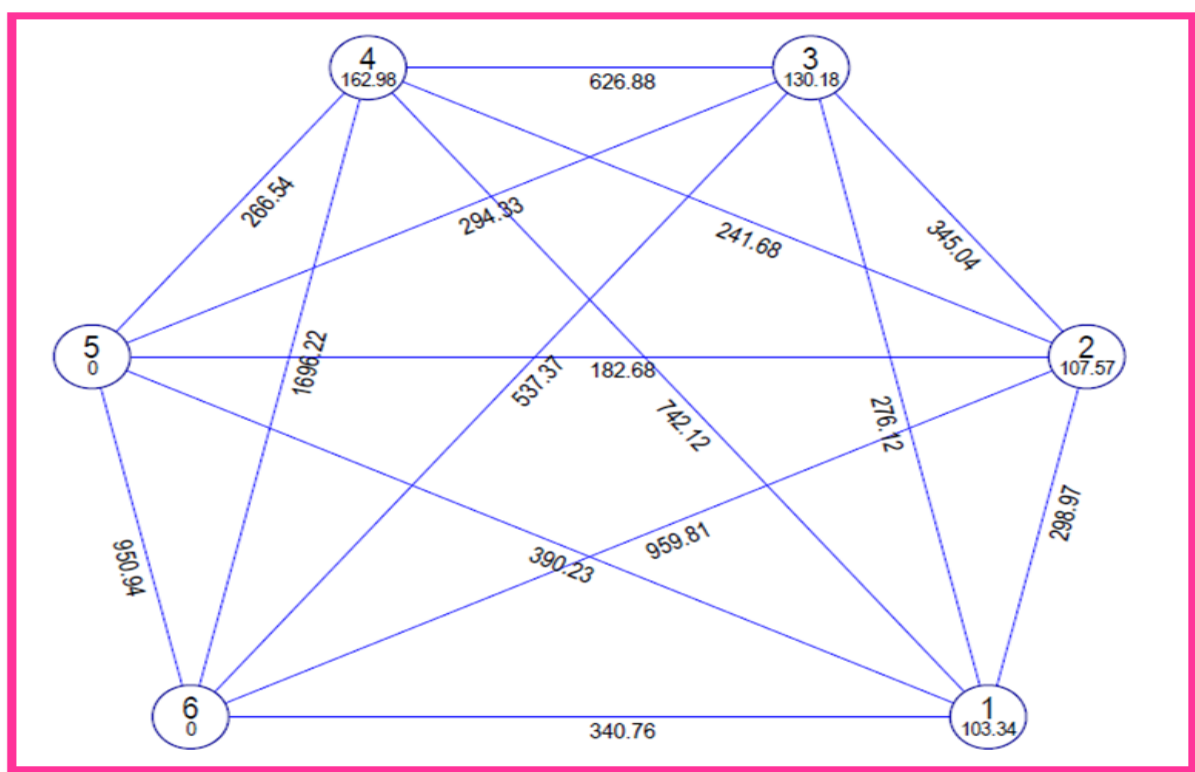

Fig.2 Average inter and intra cluster distances under rainfed condition 
Cooking time for soaked seeds $(69.66 \%)$ has the highest contribution for genetic divergence, followed by cooking time for raw seeds $(8.51 \%)$, shoot biomass per plant (6.90\%), days to physiological maturity (5.96\%), 100 grain volume $(2.76 \%)$ and 100 seed weight $(2.53 \%)$.

The traits like days to $50 \%$ flowering $(0.23 \%)$, number of primary branches per plant $(0.23 \%)$ and number of pods per plant $(0.23 \%)$, followed by protein content $(0.46 \%)$ and seed yield per plant $(0.46 \%)$, followed by SCMR $(0.69 \%)$, seed diameter $(0.69 \%)$ and water absorption after soaking (0.69\%) contributed the least for genetic divergence. Plant height, number of secondary branches per plant, number of seeds per plant, volume expansion after soaking and harvest index showed zero contribution towards the genetic divergence.

\section{Genotypes identified as parents for further breeding programme}

The choice of parents belonging to the maximum divergent clusters is expected to manifest maximum heterosis in crossing and wide variability in genetic architecture (Chaudhry et al., 2002).

Hence, from the above findings, the genotypes viz., ICCV 171314, Vihar, NBeG 1010, ICCV 171313, Phule G 0517 from cluster IV were with high cluster means for number of pods per plant, number of seeds per plant and seed yield per plant and $\mathrm{NBeG}$ 805 genotype from cluster VI were with superior cluster means for SCMR, number of primary per plant, 100 grain volume and cooking time for soaked seeds.

Both these clusters were with maximum divergence for inter cluster distance and cluster IV has maximum intra cluster distance also. Whereas, MNK 1 genotype included in cluster V was with highest cluster mean for 100 seed weight (important trait to be selected for large seeded kabuli) and hence any of these promising genotypes belonging to these clusters can be utilized as parents for hybridization programme.

\section{References}

Chaudhry, M.A., Vanderberg, $\mathrm{V}$ and Warkentin, T. 2002. Cultivar identification and genetic relationship among selected breeding lines and cultivars in chickpea (Cicer arietinum L.). Euphytica. 172: 317-325

Gediya, L.N., Patel, D.A., Parmar, D.J., Patel, R and Parth, R. 2018. Assessment of genetic diversity of chickpea genotypes using $\mathrm{D}^{2}$ statistics. International Journal of Chemical Studies. 6(4): 3177-3181.

Jain, S and Indapurkar, Y.M. 2013. Assesment of Genetic Divergence in Chickpea Genotypes (Cicer arietinum L.). Trends in Biosciences. 6(1): 68-69.

Jayalakshmi, V., Ronald, G and Lakshmanna, K. 2014. Diversity analysis of chickpea germplasm in scarce rainfall zone of Andhra Pradesh, India. Legume Research. 37(6): 682-684.

Puri, M.K., Johnson, P.L and Sharma, R.N. 2013. Study of variability, diversity and association analysis of chickpea (Cicer arietinum L.) germplasm under normal and late sown condition of Chattisgarh state. Trends in Biosciences. 6(6): 723731.

Singh, D.J., Singh, R and Kamble, M.S. 2016. Genetic diversity studies in chickpea (Cicer arietinum L.) in kolhapur region of Maharashtra. Bangladesh Journal of Botany. 45(3): 459-464.

Syed, M.A., Islam, M.R., Hossain, M.S., Alam, M.M and Amin, M.N. 2012. Genetic divergence in chickpea (Cicer arietinum L.). Bangladesh Journal of Agricultural Research. 37(1): 129-136. 


\section{How to cite this article:}

Manasa, B., M. Shanthi Priya, V. Jayalakshmi and Umamaheswari, P. 2020. Assessment of Genetic Diversity in Extra Large and Large Seeded Kabuli Chickpea. Int.J.Curr.Microbiol.App.Sci. 9(04): 833-840. doi: https://doi.org/10.20546/ijcmas.2020.904.100 